\title{
Selection of peptides for serological detection of equine infectious anemia
}

\author{
E.M. Santos ${ }^{1}$, R. Cardoso ${ }^{2}$, G.R.L. Souza ${ }^{3}$, L.R. Goulart ${ }^{2}$, \\ M.B. Heinemann ${ }^{1}$, R.C. Leite ${ }^{1}$ and J.K.P. Reis ${ }^{1}$ \\ ${ }^{1}$ Departamento de Medicina Veterinária Preventiva, Escola de Veterinária, \\ Universidade Federal de Minas Gerais, Belo Horizonte, MG, Brasil \\ ${ }^{2}$ Instituto de Genética e Bioquímica, Universidade Federal de Uberlândia, \\ Uberlândia, MG, Brasil \\ ${ }^{3}$ Departamento de Bioquímica e Biologia Molecular, \\ Instituto de Ciências Biológicas, Universidade Federal de Goiás, \\ Goiânia, GO, Brasil
}

Corresponding author: E.M. Santos

E-mail: elmaira27@yahoo.com.br

Genet. Mol. Res. 11 (3): 2182-2199 (2012)

Received August 1, 2011

Accepted February 9, 2012

Published May 24, 2012

DOI http://dx.doi.org/10.4238/2012.May.24.2

\begin{abstract}
Equine infectious anemia caused by equine infectious anemia virus is an important disease due to its high severity and incidence in animals. We used a phage display library to isolate peptides that can be considered potential markers for equine infectious anemia diagnosis. We selected peptides using IgG purified from a pool comprised of 20 sera from animals naturally infected with equine infectious anemia virus. The diagnostic potential of these peptides was investigated by ELISA, Western blot and dot blot with purified IgG and serum samples. Based on the results, we chose a peptide mimetic for glycoprotein gp45 epitopes of equine infectious anemia virus, with potential for use as an antigen in indirect diagnostic assays. Synthesis of this peptide has possible applications for the development of new diagnostic tools for this disease.
\end{abstract}

Key words: Diagnosis; Equine infectious anemia; Peptide; Phage display 


\section{INTRODUCTION}

Equine infectious anemia (EIA) is an illness resulting from the persistent infection by the equine infectious anemia virus (EIAV), which is a member of the family Retroviridae and genus Lentivirus. EIAV presents three main structural-functional genes gag, pol and env and also a high mutation capacity generating the arousal of distinct viral variants that may get rid of hostage immune control (Leroux et al., 2001; Howe et al., 2002), hampering diagnosis and development of vaccines. EIA has no treatment or effective vaccine and disease control is carried out by diagnosis followed by identification, isolation and sacrifice, segregation, and transit restriction of seropositive animals (Sellon et al., 1994; Cook et al., 1996, Brangan et al., 2008). The disease is considered one of the main obstacles for horse raising in Brazil due to impossibility of national and international trade of the animals.

The most frequently tests used for EIA diagnosis are AGID and ELISA but several factors may cause inconsistent results that need to be confirmed by more sensitive and specific techniques (Soutullo et al., 2001; Trono et al., 2001; Leroux et al., 2004; Paré and Simard, 2004; Alvarez et al., 2007a, Cappelli et al., 2011). Techniques such as PCR and Western blot have been developed, evaluated and utilized as complementary tests or confirmations for EIA, as well as for other retroviruses (Johnson et al., 1998; Choi et al., 2002; Alvarez et al., 2007a). A low sensitivity or specificity of diagnostic test may yield false results making the efforts more complex in the control and eradication of diseases (Trono et al., 2001), and alternative antigen production methodologies for being utilized in serologic diagnosis may produce enhancements in the techniques and consequent improvement of the programs for EIA control and eradication.

According to the World Organization for Animal Health, the AGID antigen used in EIA diagnosis may be prepared from spleen cell cultures of the EIAV-infected equines in the acute phase of the disease or from a recombining expression system (Coggins et al., 1972; Nakajima and Ushimi, 1971; Alvarez et al., 2007b). Nevertheless, the classic method for preparation of EIAV antigens from spleen or dermis cell cultures from equines has an enormous disadvantage, because it can be contaminated by proteins from the cell culture or from the host, which may generate non-specific results in diagnostic tests. Besides, EIAV cultures are time-consuming and costly for large-scale antigen production (Alvarez et al., 2007b). A number of factors must be considered in the selection of antigenic preparations, such as time spent, the amount of material needed, the complexity and purity of viral proteins, the equipment available, and the costs for obtaining the final product (Llames et al., 2000).

The phage display technique was utilized in this study to identify antigenic epitopes from EIAV for use as antigens in serological diagnosis for EIA (Folgori et al., 1994; Leong et al., 2008). In this technique, proteins or peptides are expressed through a fusion to the bacteriophage proteins found on its surface, while the DNA that codifies the fused polypeptide is inside the phage. The phages presenting the peptides are submitted to interaction with immobilized antibodies in a solid support. The ligants are eluted and may be enriched for various cycles of selection by affinity. The identity of selected peptides may be determined by sequencing the inserts present in the genome of the recombining phage (Smith and Scott, 1993). When the receptor used for selection by affinity is an antibody the selected peptides from a randomic library are considered mimetic in relation to the natural corresponding epitope (Smith and Petrenko, 1997). The use of mimetic peptides like antigens in the diagnosis 
presents advantages over the use of natural antigens, because they make a specific focus possible and eliminate the cross-reactions in the diagnosis (Smith and Petrenko, 1997).

Due to the economic damage caused by EIA and the importance of the laboratorial diagnosis for the improvement of prevention and erradication activities related to the disease, in this study, peptides presented by phages were selected through phage display technology and by immune assays for discovering mimetic epitopes for EIAV.

\section{MATERIAL AND METHODS}

\section{Purifying positive and negative IgGs from equine sera}

Equine serum samples, from the Retrovirus Laboratory collection of the Department of Preventive Veterinary Medicine of Federal University of Minas Gerais, were tested for EIA diagnosis by ELISA with recombinant protein gp90 (rgp90) according to Reis (1997) and using AGID according to the protocol by Coggins et al. (1972) and adaptations by Nakajima and Ushimi (1971).

A pool comprising 20 sera from EIAV naturally infected animals and another pool comprising 20 negative sera were utilized to purify positive and negative IgG samples by affinity chromatography using Hitrap Protein G HP columns, in an ÄKTA system, following manufacturer instructions (GE Healthcare ${ }^{\circledR}$ ). After elution of the column the positive and negative IgG portions obtained were neutralized using buffer $1 \mathrm{M}$ Tris- $\mathrm{HCl}, \mathrm{pH}$ 8.0, lyophilized and resuspended in deionized/sterilized water. The concentrations of purified IgG and $\operatorname{rgp} 90$ were estimated by spectrophotometry at $280 \mathrm{~nm}$ and using the Bradford method (Bradford, 1976). The samples were submitted to electrophoresis on 16\% SDS-PAGE and stained with Coomassie-blue R-250. The molecular weight marker Bench Mark Protein Ladder (Invitrogen) was used for comparison.

\section{Biologic selection (biopanning)}

The library Ph.D.-C7C ${ }^{\mathrm{TM}}$ New England BioLabs ${ }^{\circledR}$ was used for selection of peptide sequences. First, $150 \mu \mathrm{L}$ negative IgG and $150 \mu \mathrm{L}$ positive IgG were added at the concen-

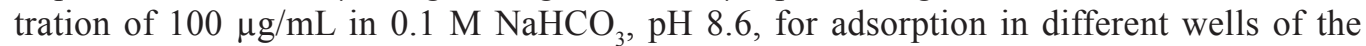
microtitration plate (MaxiSorp ${ }^{\mathrm{TM}}$ - Nunc) for $18 \mathrm{~h}$ at $4^{\circ} \mathrm{C}$. The adsorption solutions were discharged and the adsorbed wells on the plate were blocked for $1 \mathrm{~h}$ at $4^{\circ} \mathrm{C}$ with $250 \mu \mathrm{L}$ blocking buffer $\left(0.1 \mathrm{M} \mathrm{NaHCO}_{3}, \mathrm{pH} 8.6,5 \mathrm{mg} / \mathrm{mL} \mathrm{BSA}, 0.02 \% \mathrm{NaN}_{3}\right)$. The wells adsorbed on the plate were washed 6 times with TBST solution $(50 \mathrm{mM}$ Tris- $\mathrm{HCl}, \mathrm{pH} 7.5,150 \mathrm{mM}$ $\mathrm{NaCl}, 0.1 \%$ Tween 20, v/v).

Phages from original library at the concentration of $4.0 \times 10^{10} \mathrm{PFU}$ were diluted in 100 $\mu \mathrm{L}$ TBST solution and added to the microtiter well adsorbed with negative IgG and incubated for $1 \mathrm{~h}$ at $4^{\circ} \mathrm{C}$, under mild agitation. The supernatant with non-linked phages was transferred to the well containing positive IgG and incubated again for $1 \mathrm{~h}$ under mild agitation at $4^{\circ} \mathrm{C}$. After incubation with positive $\operatorname{IgG}$, the non-linked phages were discharged and the well was washed 10 times with TBST. The phages linked in this target were eluted with a buffer containing $0.2 \mathrm{M}$ glycine- $\mathrm{HCl}, \mathrm{pH} 2.2$, and $1 \mathrm{mg} / \mathrm{mL} \mathrm{BSA}$ for $10 \mathrm{~min}$ under agitation at $4^{\circ} \mathrm{C}$. The eluate was transferred to microtubes and neutralized with $2 \mu \mathrm{L}$ of the buffer $1 \mathrm{M}$ Tris- $\mathrm{HCl}, \mathrm{pH}$ 9.1. 
Aliquots of the eluted phages were utilized for determination of titers. The remaining eluate containing phages was utilized for the amplification through the infection in Escherichia coli ER2738. Four selection cycles were performed for the enrichment of the phages containing the linking peptides. From the 2 nd cycle, the washing buffer stringency increased from 0.1 to $0.5 \%$ with Tween- 20 . The procedures for biopanning, amplification, precipitation, titration, and DNA purification of the phages were performed according to instructions from the manufacturer (New England BioLabs ${ }^{\circledR}$ ).

\section{Sequencing and analyses}

For sequencing reaction $500 \mathrm{ng}$ template DNA (DNA of each phage), 5 pmol -96 gIII primer (5'-OH CCC TCATAG TTA GCG TAA CG-3' - Biolabs) and Premix (DYEnamic ET Dye Terminator Cycle Kit - Amersham Biosciences) were used. The reaction was carried out on a plate thermocycler (MasterCycler - Eppendorf). The sequencing was carried on a MegaBace 1000 (Amersham Biosciences) and DNA sequences obtained from the automatic sequencer were processed by the software of the equipment (Sequence Analyzer, Base Caller, Cimarron 3.12, Phred 15).

Analyses of deduction in silico were performed with the peptide sequences using the DNA2PRO program (available at the RELIC software, https://relic.bio.anl.gov/programs. aspx). The AAFREQ program (available at the RELIC software, https://relic.bio.anl.gov/aafreqs.aspx) was used to calculate the frequency and diversity of amino acids inside the population of selected peptides. The search for similarities between the peptides selected was accomplished through multiple alignments using the Clustal W version 18.1 software (available at www.ebi.ac.uk/clustalW/) (data not shown).

\section{Wild phage}

The phage M13KE (New England BioLabs ${ }^{\circledR}$ ) was used as a negative control for immunoassays. This phage does not present the peptide fused at protein III of the viral capsid. According to the manufacturer information, this clone may be useful as a control or in titration of phage stocks. The procedures of amplification, precipitation and titration of the wild phage were the same used for the phages selected from the libraries.

\section{ELISA A}

Precipitated phage samples were submitted to ELISA tests aiming to select only reactive phages with IgG from sera of EIAV-positive animals and non-reactive with IgG from EIAV-negative animals. High-affinity microtitration plates (MaxiSorp ${ }^{\mathrm{TM}}$ - Nunc) were adsorbed with positive and negative IgG. Forty-four wells were adsorbed for $2 \mathrm{~h}$ at $37^{\circ} \mathrm{C}$ with $1 \mu \mathrm{g}$ positive IgG and another 44 wells of the same plate were adsorbed with $1 \mu \mathrm{g}(100 \mu \mathrm{L} /$ well) of negative $\operatorname{IgG}$ diluted in bicarbonate buffer $\left(0.1 \mathrm{M} \mathrm{NaHCO}_{3}, \mathrm{pH} 8.6\right)$. Wells in each half of the plate were use as reaction controls without IgG adsorption. The plates were blocked for $18 \mathrm{~h}$ at $4^{\circ} \mathrm{C}$ using $300 \mu \mathrm{L} /$ well $5 \%$ PBS/BSA $(0.13 \mathrm{M} \mathrm{NaCl}, 0.002 \mathrm{M} \mathrm{KCl}, 0.008 \mathrm{M}$ $\mathrm{Na}_{2} \mathrm{HPO}_{4} .12 \mathrm{H}_{2} \mathrm{O}, 0.014 \mathrm{M} \mathrm{KH}_{2} \mathrm{PO}_{4}, \mathrm{pH} 7.4,5 \% \mathrm{BSA}$ ), and washed 3 times with $0.1 \%$ PBST (PBS solution $+0.1 \%$ Tween 20 ). 
Phage samples were diluted to the concentration of $1 \times 10^{11} \mathrm{PFU}(100 \mu \mathrm{L} /$ well $)$ in a solution of $0.5 \% \mathrm{PBST} / 3 \% \mathrm{BSA}\left(0.13 \mathrm{M} \mathrm{NaCl}, 0.002 \mathrm{M} \mathrm{KCl}, 0.008 \mathrm{M} \mathrm{Na}_{2} \mathrm{HPO}_{4} \cdot 12 \mathrm{H}_{2} \mathrm{O}\right.$, $0.014 \mathrm{M} \mathrm{KH}_{2} \mathrm{PO}_{4}, \mathrm{pH} 7.4,0.5 \%$ Tween 20, 3\% BSA), and dilutions of each phage sample (in duplicate) were incubated in wells adsorbed with positive and negative IgG for $2 \mathrm{~h}$ at $37^{\circ} \mathrm{C}$. The wild phage (negative control) was added on the adsorbed and non-adsorbed wells. The plates were washed 8 times with $0.1 \%$ PBST solution and incubated for $1 \mathrm{~h}$ at $37^{\circ} \mathrm{C}$ with antibody anti-M13 conjugated to peroxidase (Sigma) diluted 1:5000 (100 $\mu \mathrm{L} /$ well) in a solution of $0.5 \%$ PBST / 3\% BSA. Plates were washed as previously described and the reaction was revealed by the addition of $0.03 \% \mathrm{H}_{2} \mathrm{O}_{2}$ and $1 \mathrm{mg} / \mathrm{mL}$ o-phenylenediamine in $0.1 \mathrm{M}$ citrate-phosphate, $\mathrm{pH}$ 5.0. The reaction was interrupted by adding sulphuric acid $(2 \mathrm{~N})$ and the optical density (OD) was determined by spectrophotometry at $490 \mathrm{~nm}$ (Titertek Multiskan Plus, Flow Laboratories, USA). The cut-off value was calculated based on the OD obtained for wild phage (cut-off $=$ wild phage average value $+2 \mathrm{X}$ the standard deviation value for wild phage). The ELISA index (EI) was calculated taking the average OD of the duplicates divided by the cut-off values. Values greater than 1 were considered to be positive. The paired $t$-test was performed in order to verify the difference between the EIs obtained using the STATA 10.0 software (http://www.stata.com/).

\section{ELISA B}

Phages selected by ELISAA were tested by using 30 positive serum samples and 30 negative serum samples for EIAV infection. The equine serum samples were previously tested using rgp90 ELISA according to Reis (1997), and by Agar Gel Immunodiffusion according to Coggins et al. (1972) and adaptations by Nakajima and Ushimi (1971). Each selected phage sample and wild phage at concentration of $1 \times 10^{11} \mathrm{PFU}(100 \mu \mathrm{L} /$ well $)$, and $1 \mu \mathrm{g}(100 \mu \mathrm{L} /$ well $)$ rgp 90 protein were diluted in $0.1 \mathrm{M} \mathrm{NaHCO}_{3}, \mathrm{pH} 8.6$, and adsorbed on microtitration plates (MaxiSorp ${ }^{\mathrm{TM}}$ - Nunc) for $18 \mathrm{~h}$, at $4^{\circ} \mathrm{C}$. The plates were washed twice with $0.05 \%$ PBST solution and blocked with PBS containing 5\% skim milk powder for $1 \mathrm{~h}$. After 3 washings, wells were incubated (in duplicate) with 30 positive serum samples and 30 negative serum samples diluted 1:500 (100 $\mu \mathrm{L} /$ well, in duplicates $)$ in PBS solution containing 1\% skim milk powder, for $1 \mathrm{~h}$ at room temperature. The wells that did not receive serum samples were considered blank reactions. After six washings, wells were incubated with the antibody anti-equine IgG conjugated to peroxidase (Sigma) diluted 1:5000 (100 $\mu \mathrm{L} /$ well) in PBS solution containing $1 \%$ skim milk powder for $1 \mathrm{~h}$, at room temperature. The plate was washed 6 times and the reaction was revealed as described for ELISAA. The OD was determined by spectrophotometry at $490 \mathrm{~nm}$ (Titertek Multiskan Plus, Flow Laboratories, USA). The cut-off value was calculated based on the OD values of the protein rgp 90 with the negative serum samples (absorbance average for rgp90 with negative serum samples plus $2 \mathrm{X}$ the standard deviation). The EI was calculated separately for positive and negative serum samples (negative EI: average absorbance of each negative serum - average for wild phage with negative sera/cut-off; positive EI: average absorbance of each positive serum - average for wild phage with positive sera/cut-off). The $t$-test was performed in order to verify the difference between the ELISA indexes obtained using the STATA 10.0 software (http://www.stata.com/).

\section{ELISA competition A}

The ELISA competition assay was performed to verify if the phages selected by 
biopanning and in ELISA A were able to compete with the protein rgp90 for binding to positive IgG samples.

The IgG-purified samples from positive sera were diluted for the concentration of 1 $\mu \mathrm{g} / \mathrm{well}$ in $0.1 \mathrm{M} \mathrm{NaHCO}_{3}, \mathrm{pH} 8.6$, and adsorbed on microtitration plates (MaxiSorp ${ }^{\mathrm{TM}}$ - Nunc) for $18 \mathrm{~h}$, at $4^{\circ} \mathrm{C}$. After 2 washes with $0.05 \%$ PBST solution, the plates were blocked using PBS solution containing 5\% skim milk powder for $1 \mathrm{~h}$, at room temperature. After blocking, the plates were washed 3 times with $0.05 \%$ PBST.

The wild phage and phage samples were diluted to a concentration of $1 \times 10^{11} \mathrm{PFU}(100$ $\mu \mathrm{L} /$ well), and rgp 90 was diluted to concentrations of $0,4,8$, and $16 \mu \mathrm{g} / \mu \mathrm{L}$ in PBS with $1 \%$ skim milk powder. Each phage sample $(100 \mu \mathrm{L})$ was mixed to each rgp90 concentration $(100 \mu \mathrm{L})$ in duplicates and incubated in the wells for $1 \mathrm{~h}$, under agitation, at room temperature. As a control of phage reaction, in 2 wells of each column were added to phage samples $\left(1 \times 10^{11} \mathrm{PFU}\right)$ without protein rgp90. The wells without samples were the blank of the reaction. Wells were washed 6 times with $0.05 \%$ PBST solution and incubated with the antibody anti-M13 conjugated to peroxidase (Sigma) diluted 1:5000 (100 $\mu \mathrm{L} /$ well) in PBS with 1\% skim milk powder. The plates were incubated for $1 \mathrm{~h}$ at room temperature and washed 6 more times.

The reaction was revealed and the OD was determined as previously described. The cutoff value was calculated based on the OD obtained for the wild phage (cut-off $=$ wild phage average value $+2 \mathrm{X}$ the standard deviation value for wild phage). The EI was calculated taking the average OD of the duplicates divided by the cut-off values. The STATA 10.0 software (http://www.stata. $\mathrm{com} /$ ) was used to calculate the variation coefficient for each phage in the experiment.

\section{Dot blot}

Nitrocellulose membranes $(0.2 \mu \mathrm{m}$, Amersham Pharmacia) were sensitized with selected phages $\left(1 \times 10^{11} \mathrm{PFU} /\right.$ well), wild phage (negative control, $1 \times 10^{11} \mathrm{PFU} /$ well), with rgp90 (positive control, $1 \mu \mathrm{g}$ ) and blocked in TBS solution with 5\% skim milk powder for $1 \mathrm{~h}$ under agitation, at room temperature. After a wash with $0.05 \%$ TBST solution $(50 \mathrm{mM}$ Tris- $\mathrm{HCl}, \mathrm{pH} 7.5,150 \mathrm{mM} \mathrm{NaCl}, 0.05 \%$ Tween 20), IgG positive and negative (400 $\mu \mathrm{g}), 40$ positive sera and 40 negative sera for EIA $(1: 1250)$ were diluted in blocking solution and incubated with each membrane for $1 \mathrm{~h}$ under agitation, at room temperature. After 5 washes, the membranes were incubated for $1 \mathrm{~h}$ with anti-equine $\mathrm{IgG}$ conjugated to alkaline phosphatase (1:5000, Sigma) diluted in blocking solution, under agitation, at room temperature. After 5 washes, the reactions were revealed by adding NBT/BCIP solution (Sigma Chemical) and interrupted by deionized $\mathrm{H}_{2} \mathrm{O}$.

\section{Dot-blot competition}

The phage samples that reacted in dot blot with positive sera and non-reacted with negative sera were submitted to the dot-blot competition test. The phages sensitized in the membranes were tested for their ability to compete with the protein rgp90, in solution, for binding to the antibodies from positive serum samples for EIAV infection.

Nitrocellulose membranes $(0.2 \mu \mathrm{m}$, Amersham Pharmacia) were cut into strips and sensitized with selected phage and wild phage (negative control) at the concentration $1 \times 10^{11}$ $\mathrm{PFU}$ and $1 \mu \mathrm{g}$ rgp90 (positive control). After the sensitization, membranes were blocked with 
TBS solution with $5 \%$ skimmed powdered milk for $1 \mathrm{~h}$, under agitation, at room temperature and washed once in $0.05 \%$ TBST. Positive and negative serum samples were diluted 1:1250 in blocking solution. The membranes were incubated for $2 \mathrm{~h}$, under agitation, at room temperature with positive sera, negative sera, and positive sera mixed with $80 \mu \mathrm{g}$ protein rgp90 (competition). After 5 washes with $0.05 \%$ TBST, the membranes were incubated for $1 \mathrm{~h}$ with anti-equine IgG conjugated to alkaline phosphatase (1:5000, Sigma Chemical) in blocking solution, under agitation, at room temperature. After 5 washes, the reactions were revealed by adding NBT/BCIP (Sigma Chemical) and interrupted with deionized $\mathrm{H}_{2} \mathrm{O}$.

\section{Western blot}

The Western blot test was used to confirm if the peptide fused to the protein III (pIII) of phages differentiates positive and negative serum samples for EIA. The selected phage $\left(1 \times 10^{12} \mathrm{PFU}\right.$ ), wild phage (negative control, $1 \times 10^{12} \mathrm{PFU}$ ) and $10 \mu \mathrm{g}$ rgp90 (positive control) were submitted to electrophoresis on SDS-PAGE (16\% acrylamide). The samples were electrotransferred for $2 \mathrm{~h}$ at $280 \mathrm{~mA}, 4^{\circ} \mathrm{C}$ to nitrocellulose membranes $(0.2 \mu \mathrm{m}$, Amersham Pharmacia) that were blocked by TBS solution with $5 \%$ skim milk powder for $1 \mathrm{~h}$ under agitation, at room temperature. After a wash with $0.05 \%$ TBST solution $(50 \mathrm{mM}$ Tris- $\mathrm{HCl}, \mathrm{pH}$ $7.5,150 \mathrm{mM} \mathrm{NaCl}, 0.05 \%$ Tween 20$)$, IgG-positive and -negative $(400 \mu \mathrm{g})$ and positive and negative serum samples for EIA (1:1500) were diluted in blocking solution and incubated in the membranes for $1 \mathrm{~h}$ under agitation, at room temperature. After 3 washes, the membranes were incubated for $1 \mathrm{~h}$ with anti-equine IgG conjugated to alkaline phosphatase (1:5000, Sigma Chemical) diluted in blocking solution, under agitation, at room temperature. After 3 washes, the reactions were revealed by adding NBT/BCIP (Sigma Chemical) and interrupted by deionized $\mathrm{H}_{2} \mathrm{O}$.

\section{ELISA competition B}

Microtitration plates (MaxiSorp ${ }^{\mathrm{TM}}$ - Nunc) were adsorbed for $18 \mathrm{~h}$ at $4^{\circ} \mathrm{C}$ with protein rgp90 $(1 \mu \mathrm{g} /$ well $)$ diluted in $0.1 \mathrm{M} \mathrm{NaHCO}_{3}, \mathrm{pH}$ 8.6. After this step, the plates were washed twice with $0.05 \%$ PBST and blocked with PBS solution containing 5\% skim milk powder for $1 \mathrm{~h}$. Positive and negative serum samples were diluted 1:500 in PBS solution containing 1\% skim milk powder and incubated in duplicate. The positive sera were diluted 1:500 and mixed with $1 \times 10^{11} \mathrm{PFU}$ of E12 and wild phage (competition), which were also incubated into the wells in duplicate. The wells without serum samples were the blank of the reaction. After a 2-h incubation, the plates were washed 6 times and the anti-equine antibody conjugated to peroxidase (1:5000, Sigma) was added. After incubation for $1 \mathrm{~h}$ and six washes, the reaction was revealed and the OD was determined as previously described. The statistical analysis of the results was carried out utilizing the Prisma 5.0 software for ANOVA with the Bonferroni test for the comparison of the averages of the duplicates of the OD values obtained through ELISA.

\section{Bioinformatics analysis}

The sequence of the selected peptide was analyzed in comparison to sequences of 
EIAV proteins stored in the "GENEBANK" through the BLAST - Basic Local Alignment Search Tool software (http://www.ncbi.nlm.nih.gov/BLAST/). To find the maximum of similarity among the selected peptide and the EIAV proteins the program MATCH (available at RELIC, http://relic.bio.anl.gov/match.aspx/) was used.

\section{Synthesis of the peptide containing mimetic epitopes of the EIAV}

At this stage the system of multiple mimetic peptides (multiple antigen peptides) based on the selected phage by phage display and immunoassays was utilized. The synthetic peptide was planned with 5 repetitions in tandem, presenting the same spacer -GGGS- and $\mathrm{C}$-terminal amide for stabilizing the peptide structure. The peptide was synthesized by Genscrip (www.genscript.com). The synthetic peptide called VAIE-E12 presents 51-amino acid residues, molecular weight $4840.2 \mathrm{kDa}$, isoelectric point 8.2 , and a positive charge $(+0.5)$ in $\mathrm{pH} 7.0$.

\section{ELISA VAIE-E12}

ELISA assays were performed to verify the VAIE-E12 reactivity with 30 samples of positive sera and 30 samples of negative sera for EIAV infection.

The synthetic peptide was diluted in sterilized deionized water and its concentration determined by spectrophotometry at $280 \mathrm{~nm}$ and by the method of Bradford (1976). Microtitration plates (MaxiSorp ${ }^{\mathrm{TM}}$ - Nunc) were adsorbed with VAIE-E12 $(0.5 \mu \mathrm{g} / \mathrm{well})$ diluted in bicarbonate buffer $\left(0.1 \mathrm{M} \mathrm{NaHCO}_{3}, \mathrm{pH} 8.6\right)$, for $18 \mathrm{~h}$ at $4^{\circ} \mathrm{C}$. After adsorption the plates were washed twice with $0.05 \%$ PBST and blocked using PBS solution containing $5 \%$ skim milk powder for $1 \mathrm{~h}$. The plates were washed twice and serum samples diluted 1:20 $(100 \mu \mathrm{L} /$ well $)$ in PBS solution containing $1 \%$ skim milk powder were incubated in duplicate. Adsorbed wells that did not receive serum sample were considered blank reactions. After the 1 -h incubation at room temperature, 6 washes with $0.05 \%$ PBST were carried out. The anti-equine antibody conjugated to peroxidase (Sigma) diluted 1:5000 (100 $\mu \mathrm{L} /$ well) in PBS solution containing $1 \%$ skimmed powdered milk was added in each well. After incubation for $1 \mathrm{~h}$ and six washes were carried out, the reaction was revealed and the OD was determined as previously described. The PRISMA 5.0 software (GraphPad, http:// www.graphpad.com/prism/) was utilized to carry out the $t$-test for evaluation of average values of the OD obtained through ELISA.

\section{RESULTS}

\section{Phage selection}

Eluates containing phages obtained by biopanning were titrated to estimate the phage quantity selected for the 4 cycles using the Ph.D.-C $7 C^{\mathrm{TM}}$ library and it was observed that titers increased gradually from the 1 st to 4 th cycle.

After sequencing, 28 peptide sequences were translated and 23 different sequences were identified, because the sequence TATSHLF was selected 4 times (4 identical phages) while the sequence GNSWYNS presented 3 repetitions. The calculations of the total frequen- 
cies for each amino acid in the peptides obtained by the AAFREQ software showed a greater frequency of hystidine, leucine and serine.

The search for similarities among the 23 different sequences was performed using the Clustal W version 18.1 software (http://www.ebi.ac.uk/clustalW/), and revealed some common motifs among the selected peptides: SHLF, ATSHxF, SHxF, THxF, and IQPLL (data not shown).

\section{ELISA A}

The reactivity between the phages and the purified IgGs was tested by ELISA A. Only phages that reacted with IgG purified from positive sera for EIA and non-reactive with IgG purified from negative sera for EIA were selected. An EI greater than 1 was considered to be positive (Figure 1). In this assay 11 clones were selected: C3, C4, C8, C9, D4, D11, E1, E12, G3, H1, and H9.

For verifying differences among the EIs obtained based on the reactivity of the 11 clones with positive and negative IgGs, the paired $t$-test was performed utilizing the STATA 10.0 software. The value for $\mathrm{P}<0.001$ showed a significant difference in the reactivity of phages with positive and negative IgGs.

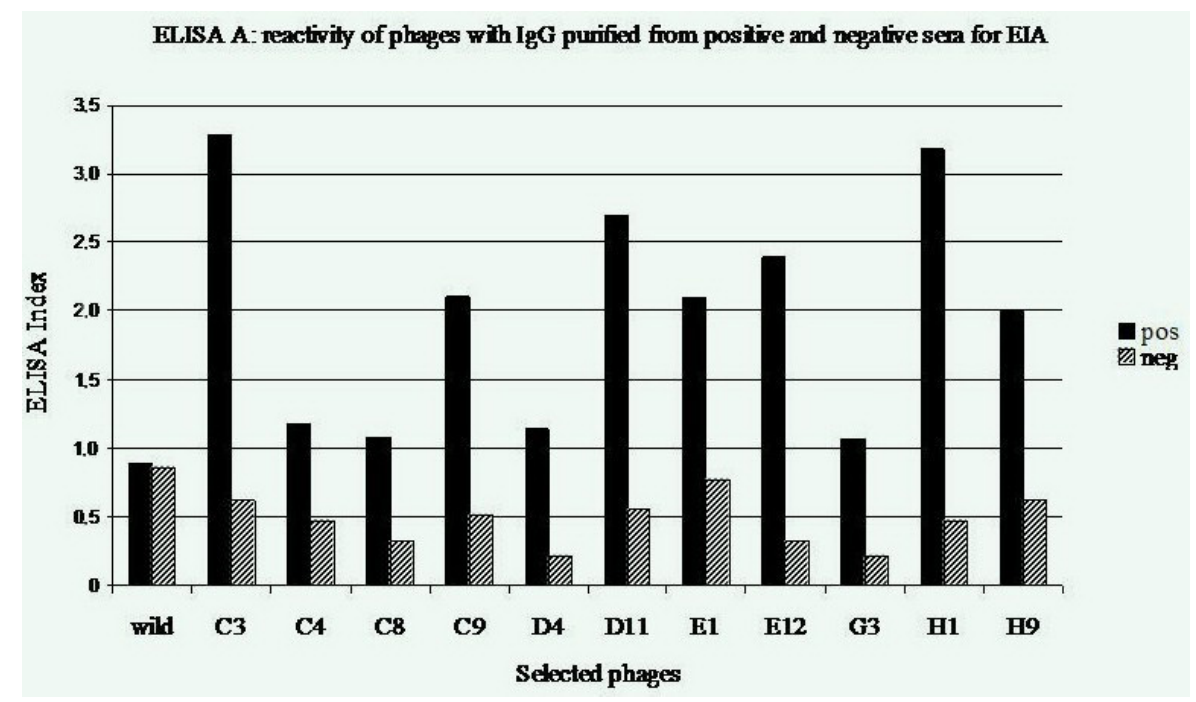

Figure 1. Selection of phages by the ELISA A test. Phages presenting the ELISA index greater than 1 for positive (pos) IgG and lower than 1 for negative (neg) IgG were selected. EIA = Equine infectious anemia.

\section{ELISA B}

ELISA B assay was performed to verify the antigenic characteristic and reactivity of the 11 phages selected by ELISA A to positive and negative serum samples for EIAV infection. Only the phage E12 and protein rgp90 were able to differentiate positive and negative sera (Figure 2) showing significant differences between average values for IE obtained with positive and negative samples ( $t$-test; $\mathrm{P}<0.001$; STATA 10.0). 


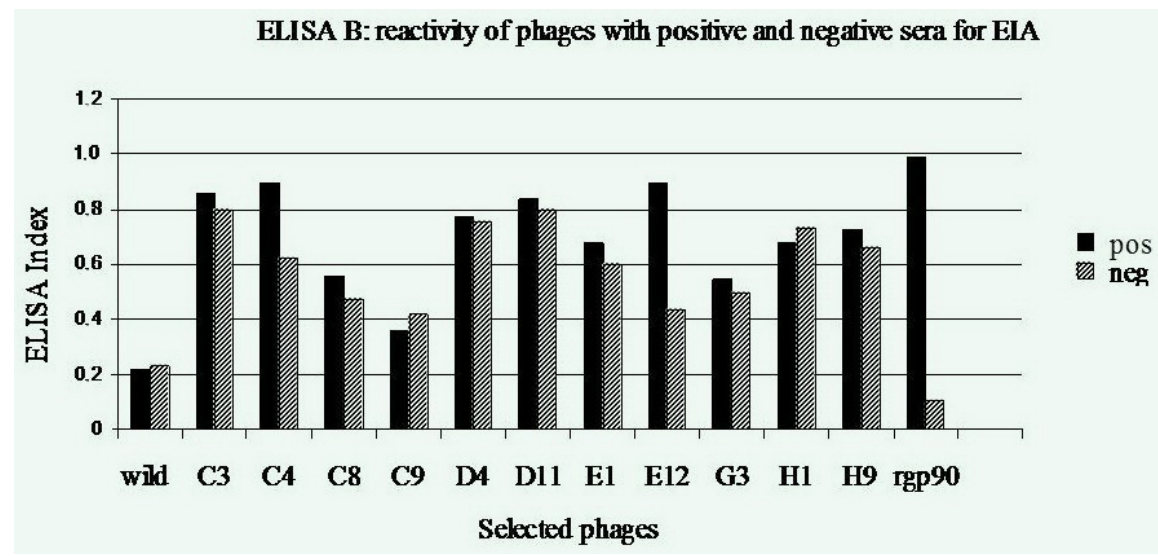

Figure 2. ELISA B: reactivity of the selected phages with 30 positive (pos) sera and 30 negative (neg) sera for equine infectious anemia (EIA) (average values of ELISA index).

\section{ELISA competition A}

According to results obtained by ELISA competition A, the increased concentrations of protein rgp90 in solution with the phages lead to a decrease in reactivity of the phages with the positive IgG adsorbed on the plate, when compared with the wells that received phage samples $\left(1 \times 10^{11} \mathrm{PFU}\right)$ without protein, showing that there is a competition between rgp90 and phages to react with the $\operatorname{IgG}$ (Figure 3). By using the STATA 10.0 software, the variation coefficient was determined in the experiment: $\mathrm{C} 3=26 \%$; $\mathrm{C} 4=45 \%$; $\mathrm{C} 8=36 \%$; $\mathrm{C} 9=33 \%$; $\mathrm{D} 4=38 \%$; $\mathrm{D} 11=31 \%$; $\mathrm{E} 1=42 \%$; $\mathrm{E} 12=83 \%$; G3 $=38 \%$; H1 $=46 \%$; H9 $=35 \%$; wild $=26 \%$, and was observed that phage E12 presented the greatest decrease upon increasing the rgp 90 concentrations, pointing to greater competition of this phage in comparison to other clones (Figure 3).

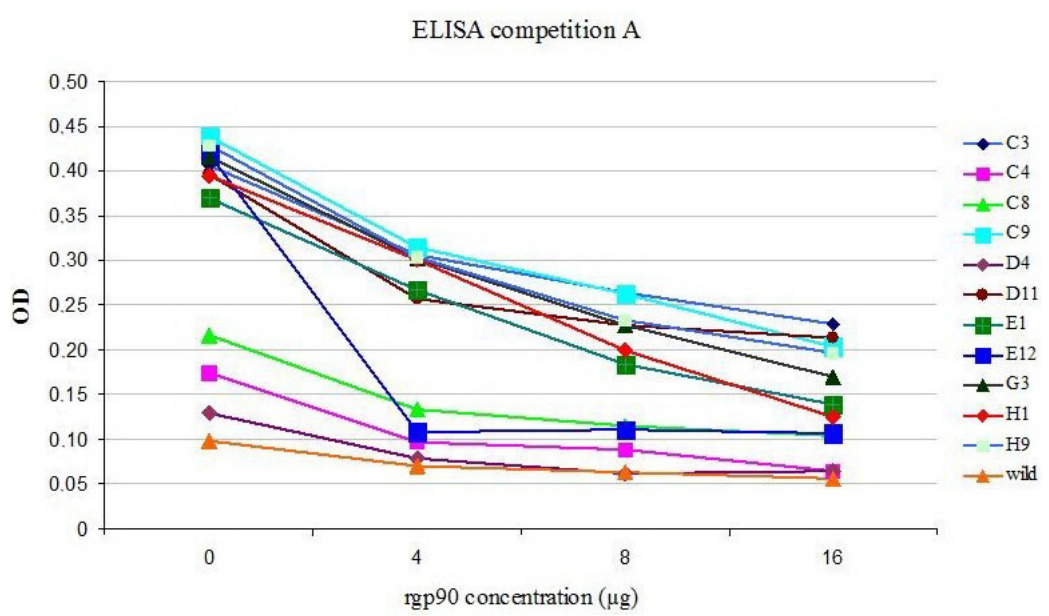

Figure 3. ELISA competition A: selected phages and rgp90 in competition to react with IgG purified from positive sera for equine infectious anemia. $\mathrm{OD}=$ Optical density. 


\section{Dot blot}

In dot-blot assays, the results were based on the intensity of staining, and the phages C4, C8, C9, E12, H1, and H9 were able to differentiate positive and negative IgG (Figure 4). For analysis with serum samples, just phage E12 was able to differentiate positive and negative sera for EIA (Figure 5). The wild phage did not react with the IgG and serum samples.

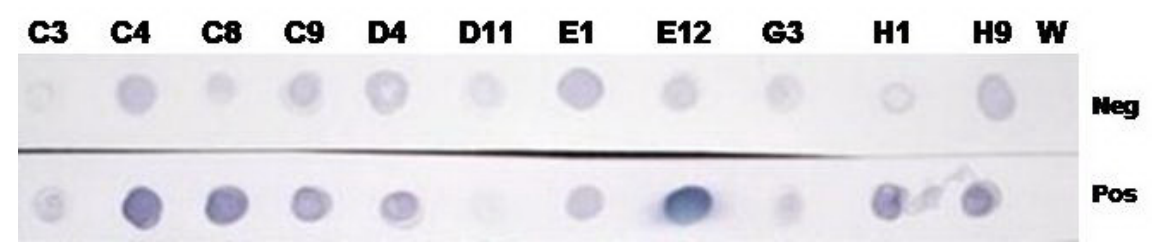

Figure 4. Evaluation of phage reactivity with $\operatorname{IgG}$ in dot blot: superior membrane incubated with negative (Neg) $\mathrm{IgG}$, and inferior membrane incubated with positive (Pos) IgG. W = Wild phage.

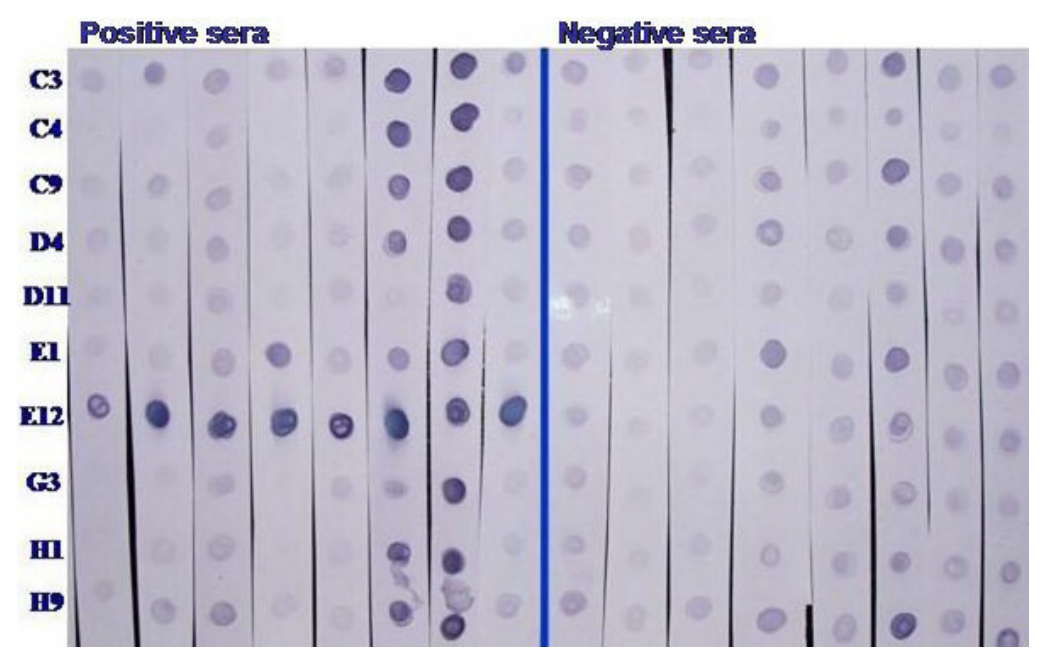

Figure 5. Evaluation of phage reactivity in dot blot with 10 positive and 10 negative serum samples for equine infectious anemia (on the left of the line: membranes incubated with positive sera; on the right of the line: membranes incubated with negative sera; C8 and wild phage did not react with serum samples; data not shown).

\section{Dot-blot competition}

Nitrocellulose membranes adsorbed with E12 phage, wild phage and rgp90 were incubated with different positive and negative serum samples and with positive sera containing 80 $\mu \mathrm{g}$ rgp90 (competition). In the membranes incubated with positive sera mixed with rgp90, the E12 phage presented low reactivity when compared with membranes incubated with positive sera only (Figure 6). The protein rgp90 (in solution) competed with E12 phage (adsorbed) to react with antibodies from positive serum samples for EIA. The rgp90 adsorbed in the membrane competed also with the rgp90 in solution, similarly to the phage. The wild phage did not react with serum samples. The E12 phage and rgp90 presented low reactivity with negative sera. 


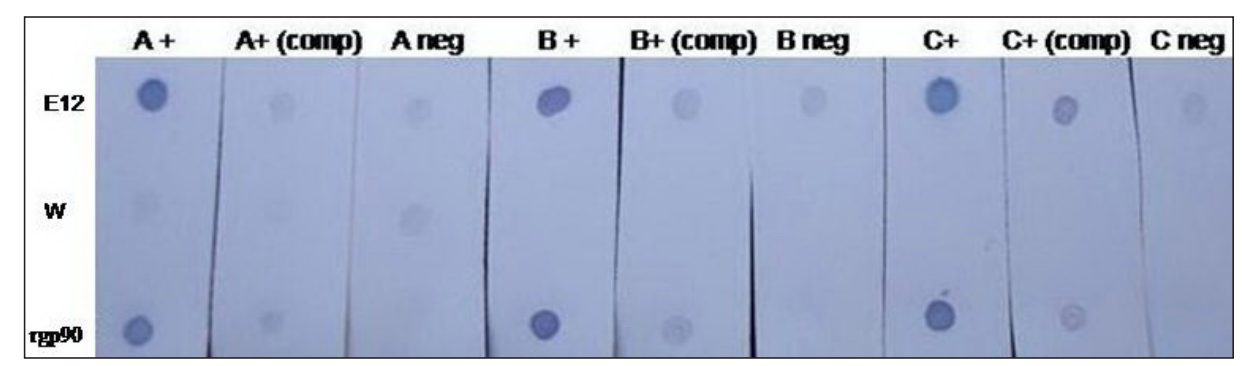

Figure 6. Dot-blot competition assay: E12 phage competing with rgp90 to react with positive sera for equine infectious anemia $[\mathrm{A}+, \mathrm{B}+, \mathrm{C}+=$ positive sera; $\mathrm{A}+(\mathrm{comp}), \mathrm{B}+(\mathrm{comp}), \mathrm{C}+(\mathrm{comp})=$ positive sera containing $80 \mu \mathrm{g}$ rgp90; A neg, B neg, C neg = negative sera; wild phage $(\mathrm{W})=$ negative control].

\section{Western blot}

Western blot test was performed to confirm if the peptide fused to the pIII of phage E12 differentiates positive and negative serum samples for EIA, and the specific reaction of the antibodies from positive sera with pIII $(\sim 42 \mathrm{kDa})$ of the phage E12 and with rgp90 was observed (Figure 7). No reactivity was detected with wild phage. According to results from the Western blot only the peptide fused on pIII of the E12 phage was specifically recognized by purified $\operatorname{IgG}$ (data not shown) and by antibodies from sera used for immunoassays, and not other sequences that constitute the viral particle of the phage.

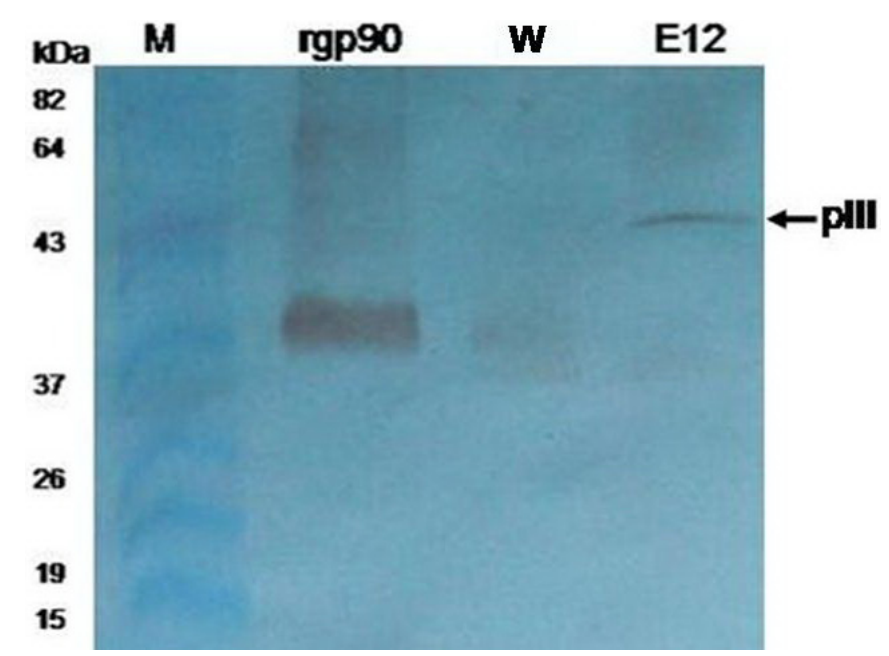

Figure 7. Nitrocellulose membrane showing Western blot results for reactivity of E12 phage, wild phage and protein rgp90 with positive serum sample for equine infectious anemia (protein III, pIII: 42 kDa; rgp90: 39 kDa; wild phage (W): negative control; lane $M=$ molecular weight marker).

\section{ELISA competition B}

The rgp90 was adsorbed in the wells of the plate and incubated with positive se- 
rum samples (positive control), negative serum samples (negative control) and with positive serum samples mixed to phage E12 (competition). This assay enabled verification that E12 phage in solution with positive serum samples competes with rgp90 adsorbed to the wells for binding to antibodies of the positive sera for EIA. This result was found due to the smaller OD obtained in the wells that contained the phage, in comparison to the wells where the same positive serum samples were applied without the phage (Figure 8). Utilizing the PRISMA 5.0 software (http://www.graphpad.com/prism/) for ANOVA with the Bonferroni method, it was possible to observe that the absorbance values were statistically different between the positive sera and the positive sera in solution with phage E12, and between the positive and negative sera $(\mathrm{P}<0.05)$.

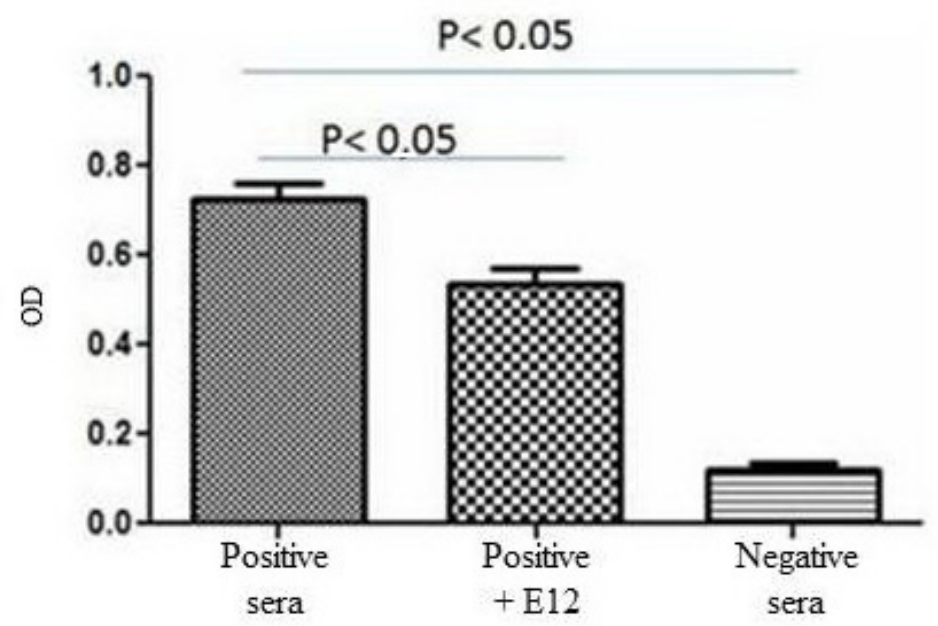

Figure 8. ELISA competition B: evaluation of results obtained by optical density (OD) for analysis of competition between E12 phage (in solution) and rgp90 (adsorbed) for binding to the antibodies from positive serum samples for equine infectious anemia.

\section{Bioinformatics analysis and synthesis of the peptide}

The sequence of the peptide fused on the E12 phage was analyzed in comparison to sequences of EIAV proteins stored at "GENEBANK" using the BLAST software (http://www. ncbi.nlm.nih.gov/BLAST/). The results showed a similarity of the peptide (TATSHLF) with the glycoprotein transmembrane gp45 coded by the env gene of EIAV (database accession Nos. AAK21107.1, AF327877.3, AAK21113.1, AF327878.1), and utilizing the MATCH software, a maximum similarity region represented by ATSH was observed (Figure 9).

According to the results of immunoassays and bioinformatics analysis, the sequence exhibited by E12 phage was selected to produce the synthetic peptide. The system of multiple mimetic peptides was utilized, and VAIE-E12 synthetic peptide was designed with 5 repetitions of the TATSHLF sequence, presenting the spacer-GGGS- and C-terminal amide:

VAIE-E12

TATSHLFGGGSTATSHLFGGGSTATSHLFGGGSTATSHLFGGGSTATSHLF- NH3 


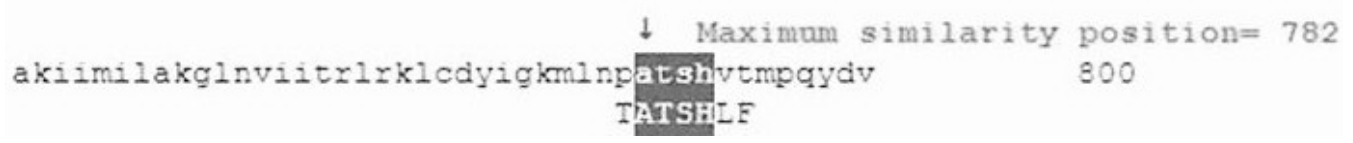

Figure 9. Maximum similarity point $(A T S H)$ between peptide fused on the E12 phage (TATSHLF) and gp45 glycoprotein of the equine infectious anemia virus.

\section{Results of the reactivity of peptide VAIE-E12 in ELISA with serum samples from animals naturally infected by EIAV}

The reactivity of the synthetic peptide VAIE-E12 was tested by ELISA. The PRISMA 5.0 software (http://www.graphpad.com/prism/) was used for the $t$-test analysis and the obtained value for $\mathrm{P}<0.0001$ showed a significant difference between results with 30 positive sera and 30 negative sera for EIAV infection (Figure 10).

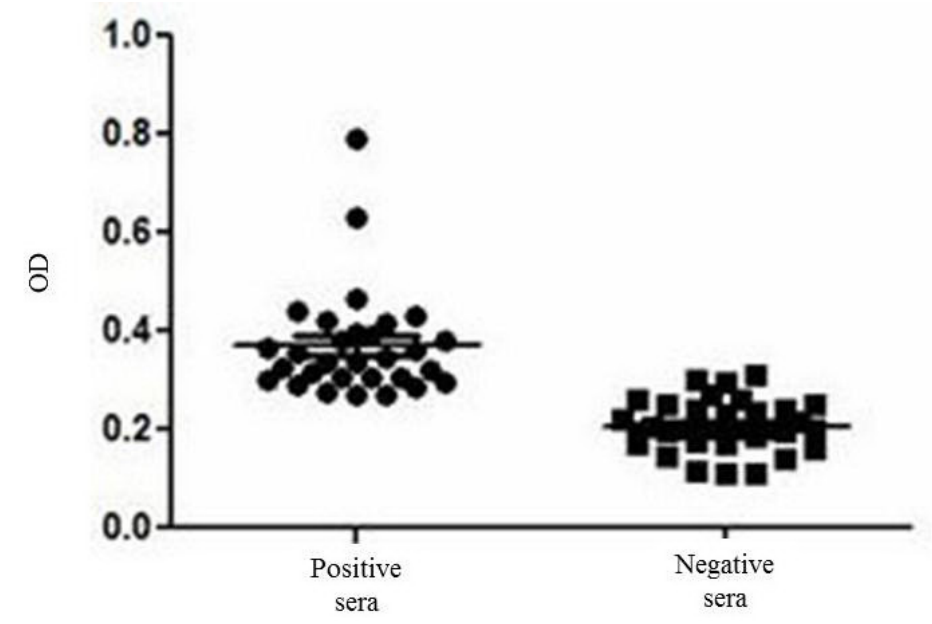

Figure 10. Evaluation of results obtained by optical density (OD) in the ELISA test using the synthetic peptide VAIE-E12 for testing 30 positive and 30 negative serum samples for EIAV infection $(t$-test; $\mathrm{P}<0.0001$; GraphPad; Prisma 5.0).

\section{DISCUSSION}

The development of suitable diagnostic techniques aiming at the improvement of measures for control and eradication of diseases has been the goal of many studies. In the case of persistent infection by EIAV, a reliable diagnostic method capable of identifying the initial phases of EIA is of major importance to prevent the spread of the virus in flocks, because the carrier animals are considered to be the source of infection for the healthy ones, since there are no vaccines that protect against all variants of the virus (Sellon et al., 1994; Cook et al., 1996; Trono et al., 2001).

Several techniques have been recently developed and utilized for AIE detection and many studies have been focused on the enhancement of the production of purer antigens to improve the sensitivity and specificity of the serologic diagnosis for disease (Sentsui et al., 2001; Trono et al., 2001; Alvarez et al., 2007a,b; More et al., 2008). 
The phage display techniques have been frequently utilized in the solution of a number of biological problems (Smith and Petrenko, 1997), from the discovery of epitopes to the development of diagnostic platforms and vaccines (Ziegler et al., 1998; Casey et al., 2009). This methodology enables the identification of new antigens without previous information about the specificity of the antibodies, avoiding the need for monoclonal antibodies for characterization (Parmley and Smith, 1988, 1989).

In the present study, the isolation of homologue peptides from those of EIAV may be explained by the repeated cycles for peptide selection out of affinity towards the purified IgG from positive sera for EIA. So, the selection and amplification cycles tend to produce the prevalence of peptides recognized by antibodies with higher titers, generating subpopulations of specific phages with affinity to positive IgG (Parmley and Smith, 1988, 1989). Phage enrichment during the selection process was also discovered because the titers increased gradually from the 1 st to the 4 th cycle, producing evidence that the selection procedure for peptides was directed to the biological target.

A higher frequency for hystidine, leucine and serine was observed in the analysis of amino acid frequency of the selected peptide sequences, implying that these are the main agents in the peptide-immunoglobulin interaction in the processes of biological selection (data not shown). The critical amino acids in peptide sequences provide indications of specificity in the process of the recognition of the ligants, and the presence of common motifs between peptides may be related to a selection favoring the ligant, from the indication that these amino acids may be critical for peptide recognition by IgGs (Cortese et al., 1995). Through the analyses of proteic alignment it was possible to observe that selected peptides contain critical residues with identity and conservation and that could imitate the structure and role of the original epitopes existing in EIAV (data not shown).

The protein rgp90, used as an antigen in the indirect ELISA test according to Reis (1997), was used as control in all experiments and showed a significant difference of reactivity between positive and negative samples in ELISA, Western blot and dot blot. The wild phage was used as a negative control in the assays since it does not present the peptide fused in the pIII (Meade and Kemper, 1988). The results obtained by Western blot showed that peptides fused on pIII of the selected phages are specifically recognized by purified IgGs (data not shown) and antibodies of positive serum samples, and not other sequences that compound the viral particle when compared to the wild phage (M13) in the site corresponding to the insert.

During procedures with the purified IgGs the E12 phage presented the ability to compete with rgp90 for linking to the IgGs, besides differentiating positive and negative IgGs in all assays. In tests using serum samples, E12 was able to differentiate all positive and negative animal sera in ELISA and dot blot and also competed with rgp90 for the linkage to the antibodies of EIAV-positive serum samples in these assays. Due to its characteristics as an antigenic sample in the immunoassays the $\mathrm{E} 12$ phage presented potential for use in diagnostic tests to detect EIAV infection using a serum sample. Through the analyses of the E12 peptide sequence for the similarity to the EIAV protein sequences available on GENBANK, the homology was observed between the peptide and the EIAV transmembrane glycoprotein gp45, coded by the gene env. The region of maximum similarity represented by ATSH seems to be integrated in the interaction of the peptide with the purified IgGs and with the antibodies of the sera used in the assays.

Animals infected by EIAV present a strong immune response against the glycopro- 
teins gp90 and gp45 (Leroux et al., 2004; Shen et al., 2005), which are frequently utilized as antigens in the serologic diagnostic tests for EIA detection. Although it is widely used as an antigen for diagnosis, the gp90 is considered as the main target of antigenic variations during the infection (Howe et al., 2005; Shen et al., 2006). This fact may compromise the diagnosis when the foreign EIAV antigen is used to detect antibodies in the sera of infected animals by an EIAV variant in different areas. Biochemical and immunological studies showed that conserved epitopes can be noticed in gp 45 , pointing to the possibility that for being a better conserved protein, the use of gp45 as an antigen for diagnosis constitutes an alternative to the problems caused by the variations found in gp90 (McGuire et al., 2000; Belshan et al., 2001).

Despite the similarity between the peptide from the E12 phage and gp45, this peptide competed with the rgp90 for reaction with antibodies in the immunoassays, and it may be due the presence of epitopes existing in the different viral proteins that cross-react with the antibodies. Although there are no similarities between the selected peptide sequence and protein gp90 from EIAV, up to now, there are no Brazilian sequences of the protein gp90 in GENBANK; thus, it would be appropriate to carry out a detailed molecular study with Brazilian EIAV isolates for a comparative analysis between sequences and verification of this hypothesis.

In the present study, according to the antigenic features observed of the peptide in the immunoassays with serum samples and with the IgGs it may be suggested as an alternative antigen in the diagnosis of EIA. The use of mimetic peptides as antigens for serological diagnosis obtained from phage display libraries has been suggested by other authors as an alternative for the use of complex viral antigens, because the small peptides may eliminate the high ratio of unwanted epitopes found in the preparations of complex antigens, thus contributing to improved diagnosis (Casey et al., 2009). Besides these factors, the use of selected peptides from libraries as controls in diagnostic immunoassays, replacing native antigens, has been suggested. The mimetic peptides may also work as precisely defined positive controls proper for use in diagnostic tests as an alternative when the original pathogen is hard to obtain or has no stability and in cases of virus presenting erratic distribution (Ziegler et al., 1998).

The results obtained using ELISA with the synthetic peptide VAIE-E12 designed from the peptide sequence presented by the E12 phage showed that phage display selection was an efficient method to produce a new antigen for EIA diagnosis. The VAIE-E12 peptide presented a significant difference in reactivity with positive and negative serum samples, which makes it a potential candidate for diagnostic usage. A wider number of samples should be evaluated for standardization of the use of this peptide in serologic tests such as ELISA.

\section{REFERENCES}

Alvarez I, Gutierrez G, Ostlund E, Barrandeguy M, et al. (2007a). Western blot assay using recombinant p26 antigen for detection of equine infectious anemia virus-specific antibodies. Clin. Vaccine Immunol. 14: 1646-1648.

Alvarez I, Gutierrez G, Vissani A, Rodriguez S, et al. (2007b). Standardization and validation of an agar gel immunodiffusion test for the diagnosis of equine infectious anemia using a recombinant p26 antigen. Vet. Microbiol. 121: 344-351.

Belshan M, Baccam P, Oaks JL, Sponseller BA, et al. (2001). Genetic and biological variation in equine infectious anemia virus Rev correlates with variable stages of clinical disease in an experimentally infected pony. Virology 279: 185-200.

BLAST. Basic Local Alignment Search Tool. Available at [http://www.ncbi.nlm.nih.gov/BLAST/]. Acessed April 25, 2009.

Bradford MM (1976). A rapid and sensitive method for the quantitation of microgram quantities of protein utilizing the principle of protein-dye binding. Anal. Biochem. 72: 248-254.

Brangan P, Bailey DC, Larkin JF, Myers T, et al. (2008). Management of the national programme to eradicate equine 
infectious anaemia from Ireland during 2006: a review. Equine Vet. J. 40: 702-704.

Cappelli K, Capomaccio S, Cook FR, Felicetti M, et al. (2011). Molecular detection, epidemiology, and genetic characterization of novel European field isolates of equine infectious anemia virus. J. Clin. Microbiol. 49: 27-33.

Casey JL, Coley AM, Parisi K and Foley M (2009). Peptide mimics selected from immune sera using phage display technology can replace native antigens in the diagnosis of Epstein-Barr virus infection. Protein Eng. Des. Sel. 22: 85-91.

Choi KY, Liu RB and Buehring GC (2002). Relative sensitivity and specificity of agar gel immunodiffusion, enzyme immunosorbent assay, and immunoblotting for detection of anti-bovine leukemia virus antibodies in cattle. J. Virol. Methods 104: 33-39.

Clustal W 18.1. European Molecular Biology Laboratory- European Bioinformatics Institute (EMBL-EBI). Available at [http://www.ebi.ac.uk/clustalW/]. Acessed April 22, 2009.

Coggins L, Norcross HL and Nusbaum SR (1972). Diagnosis of equine infectious anemia by immunodiffusion test. $\mathrm{Am}$. J. Vet. Res. 33: 11-18.

Cook RF, Issel CJ and Montelaro RC (1996). Virus Infections of Equines. In: Equine infectious anemia (Studdert MJ, ed.). Elsevier, Amsterdam, 297-323.

Cortese R, Monaci P, Nicosia A, Luzzago A, et al. (1995). Identification of biologically active peptides using random libraries displayed on phage. Curr. Opin. Biotechnol. 6: 73-80.

Folgori A, Tafi R, Meola A, Felici F, et al. (1994). A general strategy to identify mimotopes of pathological antigens using only random peptide libraries and human sera. EMBO J. 13: 2236-2243.

Howe L, Leroux C, Issel CJ and Montelaro RC (2002). Equine infectious anemia virus envelope evolution in vivo during persistent infection progressively increases resistance to in vitro serum antibody neutralization as a dominant phenotype. J. Virol. 76: 10588-10597.

Howe L, Craigo JK, Issel CJ and Montelaro RC (2005). Specificity of serum neutralizing antibodies induced by transient immune suppression of inapparent carrier ponies infected with a neutralization-resistant equine infectious anemia virus envelope strain. J. Gen. Virol. 86: 139-149.

Johnson M, Rommel F and Mone J (1998). Development of a syncytia inhibition assay for the detection of antibodies to bovine leukemia virus in naturally infected cattle; comparison with Western blot and agar gel immunodiffusion. $J$. Virol. Methods 70: 177-182.

Leong YH, Devi S and Lin TK (2008). Mimotopes of heat shock proteins of Salmonella enterica serovar Typhi identified from phage-displayed peptide library. J. Infect. Dev. Ctries. 2: 313-323.

Leroux C, Craigo JK, Issel CJ and Montelaro RC (2001). Equine infectious anemia virus genomic evolution in progressor and nonprogressor ponies. J. Virol. 75: 4570-4583.

Leroux C, Cadoré JL and Montelaro RC (2004). Equine Infectious Anemia Virus (EIAV): what has HIV's country cousin got to tell us? Vet. Res. 35: 485-512.

Llames L, Gomez-Lucia E, Domenech A, Suarez G, et al. (2000). Analysis by sodium dodecyl sulfate polyacrylamide gel electrophoresis and Western blot of nonspecific and specific viral proteins frequently detected in different antigen preparations of bovine leukemia virus. J. Vet. Diagn. Invest. 12: 337-344.

McGuire TC, Leib SR, Lonning SM, Zhang W, et al. (2000). Equine infectious anaemia virus proteins with epitopes most frequently recognized by cytotoxic T lymphocytes from infected horses. J. Gen. Virol. 81: 2735-2739.

Meade DA and Kemper B (1988). Chimeric Single-Stranded DNA Phage-Plasmid Clonic Vectors. In: Vectors: a Survey of Molecular Cloning Vectors and Their Uses (Rodriguez RL and Denhardt DT, eds.). Butterworth-Heinemann, Boston, 50-97.

More SJ, Aznar I, Bailey DC, Larkin JF, et al. (2008). An outbreak of equine infectious anaemia in Ireland during 2006: investigation methodology, initial source of infection, diagnosis and clinical presentation, modes of transmission and spread in the Meath cluster. Equine Vet. J. 40: 706-708.

Nakajima H and Ushimi C (1971). Immunodiffusion studies of purified equine infectious anemia virus. Infect. Immun. 3: 373-377.

Paré J and Simard C (2004). Comparison of commercial enzyme-linked immunosorbent assays and agar gel immunodiffusion tests for the serodiagnosis of equine infectious anemia. Can. J. Vet. Res. 68: 254-258.

Parmley SF and Smith GP (1988). Antibody-selectable filamentous fd phage vectors: affinity purification of target genes. Gene 73: 305-318.

Parmley SF and Smith GP (1989). Filamentous fusion phage cloning vectors for the study of epitopes and design of vaccines. Adv. Exp. Med. Biol. 251: 215-218.

PRISMA 5.0. GraphPad Prism. Available at [http://www.graphpad.com/prism/]. Acessed March 13, 2009.

Reis JKP (1997). Produção de Antígenos Recombinantes gp90 e p26 do Vírus da Anemia Infecciosa Equina para Uso em Imunodiadnóstico. Doctoral thesis, Escola de Veterinária, UFMG, Belo Horizonte.

RELIC. Receptor Ligand Contacts Database. Available at [https://relic.bio.anl.gov/programs.aspx]. Acessed March 22, 2009. 
Sellon DC, Fuller FJ and McGuire TC (1994). The immunopathogenesis of equine infectious anemia virus. Virus Res. 32: 111-138.

Sentsui H, Inoshima Y, Murakami K, Akashi H, et al. (2001). Cross reaction of recombinant equine infectious anemia virus antigen to heterologous strains and application for serological survey among horses in the field. Microbiol. Immunol. 45: 45-50.

Shen T, Liang H, Tong X, Fan X, et al. (2006). Amino acid mutations of the infectious clone from Chinese EIAV attenuated vaccine resulted in reversion of virulence. Vaccine 24: 738-749.

Smith GP and Scott JK (1993). Libraries of peptides and proteins displayed on filamentous phage. Methods Enzymol. 217: 228-257.

Smith GP and Petrenko VA (1997). Phage display. Chem. Rev. 97: 391-410.

Soutullo A, Verwimp V, Riveros M, Pauli R, et al. (2001). Design and validation of an ELISA for equine infectious anemia (EIA) diagnosis using synthetic peptides. Vet. Microbiol. 79: 111-121.

STATA 10.0. Data Analysis and Statistical Software. Available at [http://www.stata.com/]. February 10, 2010.

Trono KG, Perez-Filgueira DM, Duffy S, Borca MV, et al. (2001). Seroprevalence of bovine leukemia virus in dairy cattle in Argentina: comparison of sensitivity and specificity of different detection methods. Vet. Microbiol. 83: 235-248.

Ziegler A, Mayo MA and Torrance L (1998). Synthetic antigen from a Peptide library can be an effective positive control in immunoassays for the detection and identification of two geminiviruses. Phytopathology 88: 1302-1305. 